UDK: 02:316.77+338.484(497.5)

Pregledni rad

Primljeno 8. rujna 2020.

\title{
Uloga knjižnica kao komunikacijskog resursa održivog turizma
}

\section{mr. sc. IVO TOKIĆ}

Hrvatsko informacijsko i dokumentacijsko društvo, Zagreb

ivo.tokic@ina.hr

dr. sc. KSENIJA TOKIĆ

Institut za turizam, Zagreb

ksenija.tokic@iztzg.hr

Održivi razvoj podrazumijeva gospodarski i društveni razvoj zajednice koji je usklađen s trajnim očuvanjem njezinih prirodnih, ljudskih i društvenih resursa tako da se čuva sklad postojećih odnosa i korištenja resursa, kao i da se omogućava njihov daljnji razvoj i korištenje u budućnosti. Kulturna baština jedan je od ključnih resursa neke zajednice koji joj daje identitet, ali i omogućava uključivanje ljudi u sve društvene i ekonomske tokove u suvremenom svijetu. Knjižnice su jedne od ključnih ustanova za očuvanje kulturne baštine neke zajednice. U ovom radu ukazuje se na mogućnosti korištenja knjižničnih potencijala kao komunikacijskih resursa razvoja održivog turizma koji bi omogućio ekonomsku i društvenu korist lokalnoj zajednici putem afirmacije njezinoga kulturnog identiteta.

Ključne riječi: knjižnice, održivi turizam, komunikacijski resursi, Hrvatska 


\section{Uvod}

Podaci o turizmu kao gospodarskoj djelatnosti jasno pokazuju da je turizam pokretač gospodarskog razvoja te da pridonosi pozitivnim ekonomskim rezultatima onih zajednica u kojima se ta djelatnost odvija. Udio turizma u svjetskom BDP-u iznosi u prosjeku $10 \%, 9 \%$ svih radnih mjesta vezano je za turističku djelatnost, omogućuje $7 \%$ izvoza roba i $30 \%$ izvoza usluga, pri čemu ostvaruje prihod od 1,5 bilijuna američkih dolara (Global Travel Media, 2019). Međutim, osim tih podataka važno je istaknuti i da se turističkom djelatnošću odvija i danas vrlo rašireni proces upoznavanja s drugim kulturama i društvima, njihovim znanstvenim, kulturnim i ostalim dostignućima i običajima te se pruža mogućnost lakše kulturne razmjene između različitih društava i približavanja među ljudima i narodima.

Ipak, uz sve pozitivne strane turizma, postoje i one negativne. Turizam je po svojoj prirodi, iako ne namjerno, destruktivna djelatnost koja na različite načine ugrožava prirodnu i kulturnu baštinu zajednica u kojima se odvija (Cunliffe, 2004). To se događa zbog izgradnje infrastrukture potrebne za odvijanje turističkih aktivnosti, zbog povećanja prometa, povećanja broja posjetitelja koji dolaze na neku destinaciju, neekoloških tehničkih rješenja vezanih za prihvat i boravak većeg broja posjetitelja, povećanja izgradnje turističkih smještanih objekata, povećanog pritiska na lokalne prirodne resurse, implementacije globalne turističke gastronomske ponude i zabavnih sadržaja nasuprot autohtone lokalne tradicije, itd. Stoga je nužno razvijati održivi turizam koji će umjereno koristiti i čuvati, kako prirodne, tako i kulturne resurse i baštinu neke lokalne zajednice te se na globalnoj razini ulažu osobiti napori u identificiranje indikatora održivog razvoja. Na osnovi koncepta održivog razvoja razvijen je koncept održivog turizma (Vukonić i Čavlek, 2001), a zbog raznovrsnih oblika turizma i njihovih pojavnosti u raznolikim i specifičnim prirodnim i društvenim okruženjima, Svjetska turistička zajednica predlaže identificiranje nacionalnih te specifičnih destinacijskih indikatora održivog razvoja turizma (Wall, 2000).

Naime, iako je baš kulturni identitet značajan resurs za razvoj turizma, on je u turizmu istovremeno i snažno ugrožen pa ga je potrebno zaštititi i sačuvati. Održivi se turizam tako može definirati kao „turizam koji u potpunosti uzima u obzir trenutne i buduće gospodarske, društvene i okolišne učinke, brine se o potrebama posjetitelja, sektora, okoliša i destinacije“ (World Tourism Organization [UNWTO], n.d.; Inicijativa Održivi turizam u Hrvatskoj, n.d.). Također, održivi se turizam definira i kao sposobnost turističke destinacije da ostane u ravnoteži s okruženjem te da ostane konkurentna na tržištu usprkos pojavi novih i manje posjećenih destinacija (Vukonić i Čavlek, 2001) te zbog toga održivi razvoj turizma podrazumijeva očuvanje kulturno-povijesne baštine. Pretpostavlja se njezino stavljanje u turističku funkciju, uz aktivnu primjenu mjera za kontrolu utjecaja korištenja u turističke svrhe na njihovo stanje (Perić i Smolčić Jurdana, 2008). Konkretnije, održivi turizam trebao bi optimalno koristiti okolišne resurse pomažući u zaštiti prirodne baštine i bioraznolikosti, poštivati i očuvati društveno-kulturnu autentičnost destinacije, kulturnu baštinu i tradicijske vrijednosti te osigurati dugoročnu održivost gospodarskih aktivnosti (Inicijativa Održivi turizam u Hrvatskoj, n.d.; Hollinshead, 2000). Na taj način održivi turizam postaje dijelom općeg pojma održivog razvoja čiji su temeljni stupovi odnos prema ekonomiji, društvenim pitanjima i pitanjima koja se odnose na okoliš i ekologiju te na kulturu kao četvrtom stupu na kojem počiva održivi razvoj (Culture 21, 2004; United Nations Educational, Scientific and Cultural Organisation [UNESCO], 2013).

Mjesta prirodne i kulturne baštine glavne su sastavnice i izvori poslovanja turističkog sektora. Štoviše, mnoga od njih upisana su na UNESCO-ov popis svjetske baštine, a interes za okoliš, kulturu i baštinu, glavna je motivacija velikog broja putnika te neprestano raste kao tržišni sektor. Knjižnice svojim 
resursima i programima pridonose promidžbi kulturnih sadržaja i komuniciranju kulturne baštine u destinacijama (UNWTO, 2011) što uvelike pridonosi razvoju održivog turizma. Kulturna baština postaje dijelom resursne osnovice za razvoj kulturnog turizma kao segmenta održivog turizma pa se u resurse održivog turizma tako ubrajaju prirodna baština, kulturna baština i financijski resursi. Iako je kulturna baština u svijetu već dugo pokretač razvoja turizma, kod nas u Hrvatskoj u većoj mjeri to polako postaje tek u posljednje vrijeme. Podaci Svjetske turističke organizacije (UNWTO, n.d.) pokazuju da je danas $37 \%$ turista motivirano za putovanja upravo kulturnim razlozima, dok domaća istraživanja (Marušić i sur., 2018) pokazuju da je u 2017. tek 12 \% turista bilo motivirano kulturnim razlozima za posjet Hrvatskoj. Međutim, i tu je prisutan polagani i blagi trend rasta jer je to za svega $2 \%$ više nego deset godina ranije. Tako se ipak može reći da, osim za prirodne resurse, turisti u Hrvatskoj pokazuju sve veći interes za kulturnim i tradicijskim atrakcijama vezanim za domaću kulturnu baštinu.

Zadnjih godina značajno raste trend segmentacije turista koji odražava različitost njihovih interesa. Tako turisti sve više traže različite atrakcije i sadržaje, npr. kulturni turisti traže kulturne, umjetničke i povijesne atrakcije i sadržaje, pustolovni turisti traže lokalne prirodne ili druge pustolovne znamenitosti, cikloturisti traže lokalne znamenitosti, kulturne sadržaje, smještaj, gastronomiju, servisne informacije, skitaoci (engl. backpackers) traže informacije o suvremenom životu lokalne zajednice, pristup internetu itd.

Prema analizi turističke sezone iz 2016. godine (Turistička zajednica Splitsko-dalmatinske županije, 2016) proizlazi da se 95 \% svih turističkih aktivnosti u Hrvatskoj odvija na obali i u mjestima uz more. Najzastupljenije turističke aktivnosti u tim područjima i danas su kupanje u moru, odlazak u restorane i slastičarnice te sudjelovanje na lokalnim zabavama (Marušić i sur., 2018). Međutim, sve se više traže i kulturni sadržaji kao što su obilazak znamenitosti, muzeja i izložbi, odlazak na koncerte i kazališne priredbe. Interes turista za lokalne kulturne sadržaje potvrđuju i podaci o tome čime su turisti nezadovoljni, a tu se ističu nedovoljna raznolikost kulturnih manifestacija i posebno tzv. program za loše vrijeme (Marušić i sur., 2018). Sve to upućuje da bi za održivi turizam u nas bilo ključno da umjesto pretežito destinacije za sunce i more, Hrvatska turistima osigura i veću i raznolikiju ponudu kulturnih sadržaja, među kojima svoje mjesto imaju i knjižnični resursi.

\section{Doprinos knjižnica u razvoju održivog turizma}

Knjižnice kao jedne od najstarijih kulturnih ustanova i dalje imaju važnu ulogu u suvremenom životu svoje zajednice omogućujući korisnicima cjeloživotno učenje, upoznavanje sa suvremenom književnom i publicističkom produkcijom, čuvanje lokalne publicističke djelatnosti kroz zavičajne zbirke, održavanjem koncerata, izložbi, predavanja itd. Na taj način one, kao ustanove koje čuvaju i grade kulturni identitet zajednice, sudjeluju u promicanju njezine kulturne baštine i kulturnog identiteta, kao i u promicanju pismenosti uključujući informacijsku, digitalnu, medijsku, ekonomsku te danas osobito važnu ekološku pismenost. Kroz edukacijske programe knjižnice educiraju i članove svoje zajednice i turiste o fizičkom, društvenom i ekonomskom okruženju te prirodnim i kulturnim vrednotama destinacije (Tokić, 2017; Tokić i Tokić, 2017a).

Značaj i utjecaj knjižnica na turističku djelatnost može u raznim primjerima biti različit, a to će ovisiti o veličini knjižnice, bogatstvu ponuđenih knjižničnih resursa i javnom ugledu, odnosno imidžu (Tokić i Tokić, 2017b; Tokić i Kranjčević, 2018; Tokić i Tokić, 2018). Koliko ta ekonomska moć može biti značajna pokazuje i primjer francuske nacionalne knjižnice Bibliothèque Nationale de France. Osim 815.000 članova korisnika koji su došli u knjižnicu tijekom 2015., u nju je iste 
godine došlo i 172.000 posjetitelja među kojima je bilo 124.000 posjetitelja izložbi, 22.500 posjetitelja drugih događanja i 11.000 posjetitelja koji su u vođenim razgledavanjima obišli knjižnicu i svratili u suvenirnice i ugostiteljske objekte u sklopu knjižnice (Bibliothèque Nationale de France, 2016). Za usporedbu, prema podacima Državnog zavoda za statistiku (2016) veliki hrvatski turistički centar grad Krk imao je iste godine otprilike jednaki broj posjetitelja (178.000), dok je primjerice drugi veliki turistički centar grad Hvar posjetilo i manje ljudi (154.000 posjetitelja).

Međutim, uloga i doprinos knjižnica u razvoju održivog turizma općenito je nedovoljno istražena tema pa je tako nedovoljno istražen i doprinos knjižnica kao komunikacijskih resursa održivog turizma. Naša su dosadašnja istraživanja pokazala da u prvom redu postoji doprinos knjižnica u razvoju turizma putem tri osnovne knjižnične funkcije kako ih definira Manifest narodnih knjižnica (International Federation of Library Associations and Institutions [IFLA] i UNESCO, 1994), a to su informacijska, kulturna i obrazovna funkcija. U mnogim društvenim zajednicama knjižnica je jedino mjesto gdje ljudi mogu pristupiti informacijama koje će, osim osobnog kulturnog uzdizanja, pomoći poboljšanju njihovog obrazovanja, naučiti nove vještine, pronaći posao, pokrenuti posao, dobiti informacije koje će im pomoći pri donošenju odluka primjerice o poljoprivredi ili zdravlju, ili dobiti informacije o zaštiti okoliša. Već i dio ovdje spomenutih informacija može biti vezan za obrazovanje i uključivanje pojedinaca u turističku djelatnost, kao i za pomoć turističkim profesionalcima za osmišljavanje novih turističkih proizvoda ili usluga. Navedenim trima funkcijama, primjerenim se marketingom knjižničnih resursa pridružuje i funkcija knjižnice kao kulturne pa onda i turističke atrakcije, a kroz sve te funkcije proteže se snaga knjižnice kao komunikatora održivog turizma.

Vezano za održivi turizam i održivi razvoj općenito, knjižnice preuzimaju svoj dio odgovornosti te kao i uvijek dosad svojim aktivnostima podržavaju i promiču pozitivne strane razvoja društva. U ovom slučaju, promiču ekološki pristup društvu čiji je sastavni dio i održivi razvoj društva pa tako i održivi turizam. Tako u okviru Hrvatskog knjižničarskog društva djeluje Radna skupina za zelene knjižnice koja pomaže Zelenim knjižnicama u promicanju i popularizaciji znanosti u svrhu zaštite planeta Zemlje. Nacionalna i sveučilišna knjižnica (NSK) posebno je aktivna na tom polju te je za uspješnu organizaciju Zelenog festivala 2018. od IFLA-e dobila 4. nagradu za zelene knjižnice svijeta. NSK je organizirala i 1. međunarodnu konferenciju o Zelenim knjižnicama svijeta, kao i seriju tribina OdrŽIVA na kojima se promiču ekološke informacije i podiže svijest javnosti za aktivnosti održivog razvoja. Slične se aktivnosti sve više održavaju po cijeloj Hrvatskoj.

Međutim, knjižnice se ne zaustavljaju samo na promicanju ekologije i podizanju svijesti o važnosti održivog razvoja. IFLA je 2018. dodijelila 1. nagradu za zelene knjižnice kineskoj gradskoj knjižnici u Foshanu na jugoistoku Kine. Osim rada na podizanju svijesti i odgoju mladih korisnika za ekološki pristup razvoju te osnaživanju starijih korisnika putem edukacija vezanih za potrebe starijih sugrađana, ta je knjižnica ekološka načela održivog razvoja primijenila kako u izgradnji zgrade knjižnice tako i u njezinom svakodnevnom radu. Najprije, prilikom gradnje nove zgrade zadovoljeno je šest ekokriterija za gradnju knjižnice: štedljivo i učinkovito korištenje zemljišta, štedljivo i učinkovito korištenje energije, štedljivo i učinkovito korištenje vode, štedljivo i učinkovito korištenje materijala, ekološka kvaliteta unutrašnjosti zgrade na dobrobit zaposlenika i korisnika te ekološko održavanje i djelovanje zelene zgrade. Povezanost s domaćom kulturnom tradicijom vidljiva je već pri samom pogledu na fasadu zgrade jer dizajnerskim rješenjima fasada odaje počast tradicionalnoj lokalnoj vještini rezanja papira, a nazivi godišnjih doba ukomponirani u razigranu fasadu podsjećaju prolaznike na povezanost s godišnjim ciklusima i prirodom. Mnogo staklenih površina služi za učinkovito korištenje prirodnog svjetla, štednju umjetne rasvjete te za učinkovitije grijanje i hlađenje. Koristi se i reciklira kišnica radi štednje vode, dok se u cijeloj zgradi pametno 
koriste samo energetski štedljivi potrošači struje. To je omogućilo da je otvaranjem novih odjela knjižnice u 2017. broj korisnika porastao za 36 dok je istovremeno potrošnja električne energije porasla samo za $12 \%$ a potrošnja vode samo za 7 \% (Foshan Library, n.d.). Ti podaci govore da je moguće naći odgovarajuća rješenja koja će osigurati održiviji razvoj nego do sada. Osim toga, knjižnice ne samo da komuniciraju sa svojom zajednicom i turističkim sektorom u smislu promocije održivog turizma, već se kroz svoje različite resurse aktivno uključuju u održivi razvoj zajednice.

\section{Primjeri hrvatskih knjižnica}

Vezano za razvoj održivog turizma koji se u našem slučaju treba temeljiti i na većoj promociji domaće kulturne baštine, knjižnice mogu ponuditi resurse koji uključuju knjižnični fond i zbirke, zgrade, kulturne programe, izložbe, koncerte, edukacijske programe, digitalizirane sadržaje, mrežne stranice, druge informacijske usluge, kao i suvenire. Naime, važno je istaknuti da se u knjižnicama čuva kulturni identitet zajednice, a da upravo kulturni identitet s baštinom kao svojom bitnom sastavnicom čini turistički proizvod atraktivnijim. Kao ilustraciju, na ovom ćemo mjestu kratko prikazati četiri primjera kako hrvatske knjižnice svojim komunikacijskim resursima pridonose promociji održivog turizma.

\section{a) Gradska i sveučilišna knjižnica Osijek (GISKO), Osijek}

\section{Baština i identitet}

Kao što sam naziv govori, radi se o knjižnici s dvojnom funkcijom. Jedna je funkcija javne, odnosno narodne knjižnice koja je ujedno i središnja matična knjižnica grada Osijeka i Osječko-baranjske županije. U tom smislu knjižnica predstavlja mjesto cjeloživotnoga učenja i najznačajnije, svima dostupno, kulturno središte lokalne zajednice koje podupire intelektualni rast i fleksibilnost u radu u skladu s informacijskim potrebama lokalne zajednice i svih njezinih članova. Kao takva, knjižnica podupire formalno obrazovanje, promiče svijest o kulturnom naslijeđu, prvenstveno zavičajnom te svijest o uvažavanju umjetnosti, znanstvenih postignuća i inovacija. Nadalje, potiče dijalog među kulturama, potiče čitateljske navike, maštu, inovativnost i kreativnost svojih korisnika, a osobito djece u suvremenom informacijskom okruženju hibridne knjižnice, postajući na taj način mjesto cjeloživotnoga učenja i najznačajnije, svima dostupno, kulturno središte lokalne zajednice. Kao središnja (matična) javna / narodna knjižnica grada Osijeka i Osječko-baranjske županije i središnja (matična) sveučilišna / znanstvena knjižnica Sveučilišta u Osijeku u provođenju svojih aktivnosti zalaže se za društveno odgovoran rad i pridržavanje najviših standarda u radu, snažnu radnu etiku, preuzimanje odgovornosti za rad i djelovanje u izgradnji međusobnih odnosa na temelju zajedništva i iskrenosti; otvorenost za nove ideje, ostvarenje što više mogućnosti koje pruža intelektualno aktivno, inovativno i fleksibilno okruženje, promicanje i poticanje otvorene komunikacije među knjižnicama u sustavu, knjižnicama i korisnicima te odlučnost u zalaganju za izvrsnost i kontinuirano poboljšavanje procesa i usluga u skladu s očekivanjem naših korisnika.

Kao sveučilišna knjižnica, značajan je i nezaobilazan čimbenik i partner u provođenju nastavnih i znanstveno-istraživačkih procesa na Sveučilištu Josipa Jurja Strossmayera u Osijeku i integrativno središte Knjižničnog sustava Sveučilišta. Kao takva, prepoznaje i prihvaća neprestane promjene u društvenom okruženju, a napose u sustavu za učenje i poučavanje, osigurava uspješan, efektivan i integriran pristup vlastitim znanstvenim resursima, kao i znanstvenim resursima drugih knjižnica unutar knjižničnog sustava Sveučilišta, ima aktivnu ulogu u nastajanju globalnih mreža knjižnica, potiče snažno povezivanje s nastavnim i znanstvenim osobljem te odgovorni rad stručnoga 
knjižničnog osoblja koje se razvija kroz usavršavanje i cjeloživotno obrazovanje i time postaje jedinstvena kategorija stručnog osoblja u sustavu visokoga obrazovanja na Sveučilištu, a GISKO značajan i nezaobilazan čimbenik te partner u provođenju nastavnih i znanstveno-istraživačkih procesa na Sveučilištu i integrativno središte Knjižničnoga sustava Sveučilišta u Osijeku.

Knjižnica je smještena u središtu grada u reprezentativnoj urbanoj vili građenoj početkom 20. st. u stilu art nouveau. To je bio vjenčani dar ugledne obitelji Gillming njihovoj kćeri Matildi kada se udala za Vjekoslava Hengla, kasnije poznatog gradonačelnika Osijeka. Knjižnica čuva i književnu ostavštinu obitelji Hengl, Rudolpha Francisa Magjera i drugih glasovitih javnih djelatnika povezanih s Osijekom. Knjižnica organizira niz javnih događanja: književne susrete, festivale, predavanja, izložbe i druge kulturne i promotivne programe. Poznata je po zbirci Austrijske knjižnice, zatim zbirkama grafike Mursiana, razglednica, geografskih karata, kao i drugim zbirkama koje svjedoče o razvoju Osijeka i tog kraja kroz stoljeća.

\section{b) Knjižnica Franjevačkog samostana, Vukovar}

\section{Sudbina naroda i sudbina knjige}

Vukovarski franjevački samostan sa župnom crkvom sv. Filipa i Jakova iz 18. stoljeća, smješten na visokoj zaravni uz Dunav, veliko je kulturno i duhovno bogatstvo. Uz župni pastoral franjevci su u 18. stoljeću u Vukovaru pokrenuli javno pučko školstvo, dok je njihov samostan provincijsko središte za studij filozofije i teologije. Zahvaljujući tim učilištima, samostanska knjižnica opremljena je vrijednim i rijetkim knjigama. Zbirka starih i rijetkih knjiga sastoji se od 343 knjige od 17. do 19. st., na hrvatskom, latinskom, njemačkom, talijanskom i mađarskom jeziku, pisanih goticom i latinicom. Posebno se ističe inkunabula Sv. Bonaventura, Questiones in IV. libros Sententiarum Petri, iz 1491. godine. Stoga vukovarska samostanska knjižnica spada među najvrjednije stare knjižnice u Hrvatskoj i jedna je od najvećih u cijeloj Hrvatskoj franjevačkoj provinciji sv. Ćirila i Metoda. Krajem 20. stoljeća imala je, prema zapisima fra Vatroslava Frkina (n.d.), 17000 svezaka literature, među kojima vrijedne knjige poput inkunabula te knjige poznatih hrvatskih pisaca iz vremena do 1850 . godine, poznate pod nazivom Rarissima Croatica. Tu su također i strane knjige pisane u razdoblju do 1600. godine, poznata djela iz 16. stoljeća, kao i nekoliko vukovarskih rukopisnih kantuala te knjiga Organum iz 18. stoljeća. Knjižnica je danas smještena u novouređenom prostoru samostana, a u svome fondu čuva knjige o teologiji, kazalištu, glazbi, filozofiji, lingvistici, gramatici, povijesti, književnosti i etici, a među kojima se ističu djela Cezara, Cicerona, Ovidija, Faventiusa, Tome Kempenca, Bartola Kašića i drugih. Također se čuva književna ostavština nekoliko respektabilnih suvremenih autora uključujući prof. Vinka Nikolića.

Posebno je zanimljiva sudbina knjižnice koja je preživjela ratna razaranja 1991. te je kao i narod Vukovara, završila 1992. u progonstvu u Srbiji da bi iz franjevačkog samostana u Zemunu bila vraćena tek 2004. godine. A baš kao i narod Vukovara, i knjige su bile gađane mecima pa čak i kopljima o čemu svjedoče one koje su sačuvane. Prema riječima fra Ivice Jagodića (2017) „,za vrijeme Domovinskog rata, knjige su doživjele sudbinu grada Vukovara i Vukovaraca. Nakon četrnaest godina progonstva, poslije potucanja od nemila do nedraga, iz Iloka, Šida, Zemuna, Beograda i Novoga Sada vraćene su u naš samostan - oštećene, prašnjave, pljesnive, propucane metcima i gelerima. Uz genocid u Vukovaru, dogodio se i kulturocid nad neprocjenjivim kulturnim bogatstvom u koje spada i franjevačka knjižnica, bogata inkunabulama i rijetkim knjigama naših pisaca i latinista do 1850. godine" (str. 27). 


\section{c) Hrvatska knjižnica i čitaonica Sali, Sali, Dugi Otok}

\section{Knjižnica na kraju svijeta, čuvarica snova}

Hrvatska knjižnica i čitaonica Sali osnovana je 1905. godine. Od 2000. godine knjižnica je profesionalizirana i ušla je u sustav hrvatskog knjižničarstva. Ta narodna knjižnica površine je svega 50-tak četvornih metara. Međutim, nalazi se na samoj rivi u središtu mjesta što ju čini najprometnijom točkom mjesta. Poznata je po svojoj otvorenosti i komunikativnosti prema korisnicima iz cijelog svijeta.

„Knjižnica u mjestu Sali na Dugom otoku! Smještena na samoj obali i otvorena do kasnih večernjih sati, mjesto je koje zrači pozitivom. Gledaju se projekcije filmova (na vanjskom zidu!), čitaju se knjige, internet za sve, svira se pijanino, igra se šah, tu je i teleskop... klinci skoro da prespavaju u tih malo kvadrata. I mi turisti smo vrlo dobrodošli.

Ako vas vjetar ponese na Dugi otok, obavezno posjetite knjižnicu Sali - tamo su figure uvijek poredane! Danijel Domazet"

Gore navedeni tekst objavio je na društvenim medijima (šah.hr, 2011) jedan od posjetitelja knjižnice. Na mrežnom mjestu Coolturnjacha (n.d.) spominju je kao „totalno drugačiju od drugih“ ističući njezinu jedinstvenu. Ova mala gradska knjižnica zaista je posebna. Ona je središnje mjesto kulturnih i društvenih zbivanja u Salima. Svakodnevno se u njoj može čuti najrazličitija glazba, sudjelovati na filmskim projekcijama i slično, što knjižnici daje posebnu atmosferu. Ideja je da knjižnica izgleda poput dnevnog boravka te se u njoj nalaze udobni naslonjači, zidovi su oblijepljeni posterima. U sklopu knjižnice djeluju kazališne i filmske skupine te je knjižnica čest domaćin, organizator i suorganizator glazbenih koncerata, filmskih ili dramskih večeri itd. Knjižnica je osobito popularna među turistima nautičarima, od kojih neki posude knjige i vrate ih tek iduće godine kada ponovno doplove. A često uz njih donesu i nove knjige kao dar knjižnici pa se u njezinom fondu nalaze knjige na različitim svjetskim jezicima, što je s jedne strane prikladno za strane turiste da nađu štivo na svom jeziku, a s druge strane i pozitivno neočekivano kad se iskrcaju s broda na nekom dalekom jadranskom otoku. Članovi knjižnice dolaze iz više od 105 domaćih i svjetskih gradova i mjesta, uključujući Karolinu od Monaka, Michaela Schumachera, Rogera Federera i druge poznate osobe iz javnog, kulturnog ili sportskog života. Knjižnicu, koliko god malenu po kvadraturi i udaljenu od središta političkih događanja, dobro poznaju i u diplomatskom zboru. Na 60-u godišnjicu tragedije u Hirošimi održani su u njoj Dani Japana kojima je nazočio i japanski veleposlanik. To samo pokazuje koliko daleko svoje resurse, u ovom slučaju ozračje i ugled može raširiti izvrsno koncipirana i vođena knjižnica. U zimskim danima knjižnica je pravi dnevni boravak gdje se organizira gledanje filmova preko projektora, gledanje utakmica (najčešće nogometnih), a u nastajanju je i književni klub po uzoru na književne klubove američkih kućanica.

\section{Knjižnični suveniri kao komunikacijski resurs}

U praktičnom utjecaju knjižnica na održivost lokalnog gospodarstva, a mimo informacija koje se mogu naći u njihovim fondovima i koje služe za razvoj novih marketinških priča i turističkih proizvoda koji će obogatiti turističku ponudu destinacije, treba istaknuti i potencijale suvenira. Suveniri su obično kupljeni predmeti u destinaciji koji nas podsjećaju na određene ljude, mjesta, događaje ili iskustva te imaju osobnu važnost za pojedinca koja je obično znatno veća od njegove tržišne vrijednosti (Cohen, 2000). Komuniciranje putem suvenira poznat je trend u svijetu muzeja. Ponuda suvenira ne služi 
samo za dodatni profit, već povećava njihovu vidljivost. Vrijednost suvenira u njihovoj je socijalnoj komponenti i emocionalnoj povezanosti s doživljenim iskustvom (Hauska \& Partner, 2017).

Knjižnični suveniri s motivima iz knjižničnog fonda i baštine, mogu značajno obogatiti turističku ponudu promicanjem autentične lokalne kulture i baštine. Uz to, mogu graditi ili razvijati kulturni identitet lokalne zajednice te pridonositi proračunu knjižnice. Uz to, angažiranjem lokalnih umjetnika ili zanatlija za izradu suvenira te drugih poduzetnika za njihovu distribuciju, mogu aktivno pridonositi i otvaranju radnih mjesta u lokalnoj zajednici.

Kao dobar primjer može se navesti korištenje npr. razglednica, plakata ili geografskih karata iz fonda knjižnice za kreiranje autentičnih suvenira te ih povezati s novim mobilnim tehnologijama kako bi se približili suvremenim turistima i širili dalje. Moguće je izraditi dekorativne predmete s prikazom pojedinih zanimljivih dijelova baštine koja se nalazi u fondu knjižnice. Mogu se kao suvenir izraditi praktični uporabni predmeti (majice, kape, držači za knjige ili olovke, stalci, vaze, olovke i kemijske olovke, šalice, oprema za mobitele i sl.) na kojima će biti aplicirani sadržaji iz fonda knjižnice koji se povezuju s lokalnom baštinom. Moguća je i poželjna duhovita suvremena interpretacija sadržaja iz lokalne baštine koja će ih na taj način lakše povezati sa svijetom i olakšati transfer lokalne baštine u neku drugu svjetsku sredinu. Moguće je izraditi praktične torbe (ili ruksake) s pozitivnim motivacijskim porukama povezanim ili s lokalnom baštinom ili s ekologijom ili samorazvojem osobnosti ili kombinirano. Može se, kao što je to napravila gradska knjižnica u New Yorku (The New York Public Library), i citirati izreke poznatih ljudi vezanih za knjižnice i ekologiju, poput ove Ciceronove: „Ako imaš vrt i knjižnicu, imaš sve što ti treba“. Neke strane velike knjižnice kao suvenir turistima nude i replike nekih praktičnih predmeta koji su pohranjeni u njihovom fondu pa je tako u gradskoj knjižnici u Chicagu (The City of Chicago Library) moguće kupiti svilene jastuke ili kišobrane koji su replika izvornih suvenira izrađenih za Svjetsku izložbu održanu 1933. u tom gradu. Glasovita gradska knjižnica u Birminghamu (The Library of Birmingham), koju godišnje posjeti nekoliko stotina tisuća posjetitelja, među mnogim suvenirima prodaje slagalicu koja predstavlja kartonski model zgrade knjižnice, koja je poznata kao biser moderne arhitekture. Istovremeno se nudi i starinski porculanski dekorativni servis za jelo, repliku izvornih servisa po kojima je poznat taj dio Velike Britanije. Memorijalna knjižnica najutjecajnijeg američkog financijera, inače bankara i kolekcionara Pierponta Morgana, The Morgan Library and Museum u New Yorku, između ostaloga posjetiteljima kao suvenir nudi posebnu mješavinu čaja Mr. Morgan’s tea u metalnoj kutiji.

\section{Zaključak}

Za daljnji uspješan razvoj domaćeg gospodarstva i društva ključno je prihvatiti ekološke postavke održivog razvoja. Na taj će se način nužno iskorištavanje resursa za dalji razvoj provoditi bez njihovoga trajnog uništavanja i uz maksimalno moguće očuvanje kako prirodnih resursa tako i tradicijske i kulturne baštine. To se odnosi i na održivi turizam koji je važan za uspješan razvoj domaćih manjih sredina kojem društvo treba težiti. Kako kulturna baština kao resurs održivog turizma u tome ima ključnu ulogu, tako je imaju i knjižnice kao mjesta očuvanja te baštine i kulturnog identiteta cijele zajednice.

Naša su dosadašnja istraživanja pokazala da u prvom redu postoji doprinos knjižnica u razvoju turizma putem tri osnovne knjižnične funkcije, a to su informacijska, kulturna i obrazovna funkcija. Ovim trima funkcijama primjerenim se marketingom knjižnih resursa može pridružiti i funkcija knjižnice ne samo kao kulturne pa onda i turističke atrakcije, već i kao značajnoga komunikacijskog resursa održivog turizma. 
Za kraj, treba se podsjetiti da je u svijetu dobro poznato kako upravo kulturni identitet s baštinom, kao svojom bitnom sastavnicom, čini turistički proizvod atraktivnijim. Budući da se održivi turizam treba temeljiti i na većoj promociji domaće kulturne baštine, knjižnice mogu ponuditi resurse koji uz dobru prateću marketinšku priču imaju potencijal postati turistička atrakcija i komunikacijski resurs održivoga turizma kao što su: knjižnični fond i zbirke, zgrade, kulturni programi, izložbe, koncerti, edukacijski programi, digitalizirani sadržaji, mrežne stranice, druge informacijske usluge, kao i suveniri.

\section{Literatura}

Bibliothèque nationale de France. (2016). Rapport d'activité 2015. Bibliothèque nationale de France. Cohen, E. (2000). Souvenir. U: J. Jafari (ur.), Encyclopedia of tourism (str. 347-348). Routledge.

Coolturnjacha (n.d.). Totalno drugačija od drugih. https://lucijapezo.wordpress.com/2012/01/08/ totalno-drugacija-od-drugih/

Culture 21. (2004). Agenda 21 for culture. http://www.agenda21culture.net/sites/default/files/files/ documents/multi/ag21 en.pdf

Cunliffe, S. K. (2004). Tourism and culture at risk. Tourism: An International Interdisciplinary Journal, 52(3), 285-291.

Državni zavod za statistiku. (2016). Priopćenje broj. 4.3.2. 9. veljače 2016. https://www.dzs.hr/Hrv Eng/publication/2015/04-03-02 01 2015.htm

Foshan Library (n.d.). Green practice of Foshan Library. https://www.ifla.org/files/assets/ environmental-sustainability-and-libraries/news/1-china_foshan_librarys_green_practice_ilovepdf.pdf

Frkin, V. (n.d.). Knjižnica franjevačkog samostana u Vukovaru. https://www.pilar.hr/wp-content/ images/stories/dokumenti/zbornici/vukovar 33/vukovar33 273.pdf

Global Travel Media. (2019). Why tourism matters. https://www.eglobaltravelmedia.com.au/saintange-tourism-report-16th-september-2019/

Hauska \& Partner. (2017). Komunikacijska strategija: Hrvatski prirodoslovni muzej, Zagreb. http:// www.hpm.hr/download/Komunikacijska\%20strategija.pdf

Hollinshead, K. (2000). Cultural conservation. U: J. Jafari (ur.), Encyclopedia of tourism (str. 123125). Routledge.

Inicijativa Održivi turizam u Hrvatskoj. (n.d.). Održivi turizam. http://www.odrzivi.turizam.hr/ default.aspx?id=97

International Federation of Library Associations and Institutions i United Nations Educational, Scientific and Cultural Organisation. (1994). Public library manifesto. https://www.ifla.org/ publications/iflaunesco-public-library-manifesto-1994

Jagodić, I. (2017). Franjevački samostan u Vukovaru - oživljena baština. @rhivi, (1), 27-29.

Marušić, Z., Čorak, S. i Sever, I. (2018). Stavovi i potrošnja turista u Hrvatskoj u 2017. godini: Tomas 2017. Institut za turizam.

Perić, J. i Smolčić Jurdana, D. (2008). Kultura, vjera, turizam - mogućnosti uspjeha na turističkom tržištu. U: N. Herceg (ur.), Međunarodna konferencija Turističke mogućnosti jadranskog zaleđa: zbornik radova (str. 85-92). Federalno ministarstvo okoliša i turizma FBIH. 
Šah.hr. (2011). Knjižnica Sali. https://sah.hr/forum/index.php?topic=825.0

Tokić, K. (2017). Knjižnice - neiskorišteni turistički resursi. U: M. Willer i D. Osrečki Jakelić (ur.), AKM 20 : mogućnosti suradnje u okruženju globalne informacijske infrastrukture: zbornik radova (str. 303-317). Hrvatsko knjižnično društvo.

Tokić, K. i Kranjčević, J. (2018). Potential of libraries as tourist attractions: Case study of Croatia. U: A. Mašek Tonković (ur.), $7^{\text {th }}$ International scientific symposium Economy of Eastern Croatia - Vision and growth: Proceedings (str. 913-921). Sveučilište Josipa Jurja Strossmayera u Osijeku, Ekonomski fakultet.

Tokić, K. i Tokić, I. (2017a). Informacijska funkcija knjižnice u turizmu: studija slučaja Hrvatske. Vjesnik bibliotekara Hrvatske, 60(4), 125-146.

Tokić, K. i Tokić, I. (2017b). Cultural heritage in libraries as a resource for the development of tourism: the case of eastern Croatia. U: A. Mašek Tonković (ur.), $6^{\text {th }}$ International scientific symposium Economy of Eastern Croatia - Vision and growth: Proceedings (str. 123-132). Sveučilište Josipa Jurja Strossmayera u Osijeku, Ekonomski fakultet.

Tokić, K. i Tokić, I. (2018). Tourism potential of libraries. Tourism: An International Interdisciplinary Journal, 66(4), 443-460.

Turistička zajednica Splitsko-dalmatinske županije. (2016). Analiza turističke sezone 2016. http:// www.dalmatia.hr/images/priopcenja/Analiza sezone 2016. godine.pdf

United Nations Educational, Scientific and Cultural Organisation. (2013). The Hangzhou declaration: Placing culture at the heart of sustainable development policies. http://www.unesco.org/new/fileadmin/ MULTIMEDIA/HQ/CLT/images/FinalHangzhouDeclaration20130517.pdf

Vukonić, B. i Čavlek, N. (2001). Rječnik turizma. Masmedia.

Wall, G. (2000). Sustainable development. U: J. Jafari (ur.), Encyclopedia of tourism (str. 367-368). Routledge.

World Tourism Organization. (2011). Communicating heritage - A handbook for the tourism sector. https://www.e-unwto.org/doi/book/10.18111/9789284413751

World Tourism Organization. (n.d.). Sustainable development of tourism. http://sdt.unwto.org/ content/about-us-5 


\section{The Role of Libraries as a Communication Resource of Sustainable Tourism}

IVO TOKIĆ, MSc

Croatian Information and Documentation Society, Zagreb

ivo.tokic@ina.hr

KSENIJA TOKIĆ, PhD

Institute for Tourism, Zagreb

ksenija.tokic@iztzg.hr

Sustainable development means such economic and social development of the community that is harmonized with the permanent preservation of its natural, human and social resources in a way that preserves the harmony of existing relations and use of resources and allows their further development and use in the future. Cultural heritage is one of the key resources of a community that gives it an identity, but also enables the inclusion of people in all social and economic trends in the modern world. Libraries are one of the key institutions for preserving the cultural heritage of a community. This paper points out the possibilities of using library potentials as communication resources for the development of sustainable tourism that would provide economic and social benefits to the local community through the affirmation of its cultural identity.

Keywords: libraries; sustainable tourism; communication resources 